\title{
LA AMPLIACIÓN DEL CORPUS DE LA LITERATURA COLONIAL CENTROAMERIANA: REFLEXIONES TEÓRICAS
}

Alexánder Sánchez Mora

\section{(c) $(1)(9)$}

Doi: https://doi.org/10.15517/rfl.v45i2.39102

URL: https://revistas.ucr.ac.cr/index.php/filyling/index 



\title{
LA AMPLIACIÓN DEL CORPUS DE LA LITERATURA COLONIAL CENTROAMERIANA: REFLEXIONES TEÓRICAS
}

\author{
THE EXTENSION OF THE CORPUS OF CENTRAL AMERICAN \\ COLONIAL LITERATURE: THEORETICAL REFLECTIONS
}

\begin{abstract}
RESUMEN
Este artículo propone la ampliación del corpus de la literatura colonial centroamericana mediante una apertura que le permita incluir textos que, desde una perspectiva genérica tradicional, habían sido definidos exclusivamente como documentos históricos. A partir de algunas propuestas del historiador Hayden White, de la estética de la recepción alemana de Hans R. Jauss y de la semántica cognitiva, se intenta mostrar cómo la larga tradición textual de las relaciones de fiestas, que abarca desde mediados del siglo XVII hasta inicios del XIX, constituye parte imprescindible de la formación discursiva literaria del barroco centroamericano.

Palabras clave: Literatura colonial; reino de Guatemala; Centroamérica; relaciones de fiestas; relaciones de sucesos.
\end{abstract}

\begin{abstract}
This article proposes expanding the corpus of Central American colonial literature through an openning that allows including texts that had been defined exclusevely as historical documents from a traditional generic perspective. Taking into account some proposals of the historian Hayden White, the aesthetics of the German reception of Hans R. Jauss, along with cognitive semantics, it is intended to show how the textual tradition of Baroque festivals, ranging from the mid-17th to the early 19th centuries, constitutes an essential part of the literary discursive formation of the Central American Baroque.

Keywords: Colonial literature; Kingdom of Guatemala; Central America; Baroque festivals; news pamphlets.
\end{abstract}

En la historiografía literaria costarricense domina la imagen de la literatura nacional como un producto de las décadas finales del siglo XIX, una discursividad nacida en el contexto de los procesos liberales de modernización política y económica y de invención de la nacionalidad. Desde esta perspectiva, los más de tres siglos del periodo colonial son identificados con un tópico del vacío discursivo, pues no habrían producido una tradición

Dr. Alexánder Sánchez Mora. Profesor Asociado de la Escuela de Filología, Lingüística y Literatura. Universidad de Costa Rica. Costa Rica. Correo electrónico: alexander.sanchez@ucr.ac.cr Recibido: 19- 04- 18

Aceptado: 24- 10- 18 
de escritura reseñable. En el contexto más amplio de lo que constituyó el antiguo reino de Guatemala, que abarcó desde el actual estado mexicano de Chiapas hasta Costa Rica, la situación es mejor, pues en Guatemala sí se produjo una buena cantidad de textos que pueden ser leídos como literarios. Aun así, la producción literaria, con todo y su riqueza, empalidece ante las dimensiones mayúsculas del acervo textual del vecino virreinato de la Nueva España.

El corpus de la literatura colonial centroamericana, y muy especialmente la costarricense, es reducido, pero la historia y la crítica literaria lo han hecho aún más reducido, pues han trabajado a partir de definiciones tradicionales de los géneros literarios. Nuestra propuesta se dirige, por lo tanto, hacia la ampliación de ese corpus, no mediante el espectacular y muy teatral descubrimiento de textos perdidos durante siglos en polvosos archivos conventuales, sino mediante una fórmula más simple e higiénica: su reformulación mediante el estudio de otros textos -las relaciones de fiestas- que durante mucho tiempo fueron concebidos tan solo como fuente de información referencial del fasto barroco, pero que pueden ser considerados como parte de la formación discursiva literaria tanto porque incorporan en su proceso de escritura recursos y temáticas propias de la ficción como porque su recepción fue similar a la de los textos reconocidos como literarios. A partir de algunas ideas del historiador Hayden White, de la estética de la recepción de Hans R. Jauss y de la semántica cognitiva, se intentará explicar cómo opera el trasvase genérico que lleva la relación de fiestas del lenguaje referencial a la ficción ${ }^{1}$.

La relación de fiesta es un género discursivo que forma parte del más amplio de las relaciones de sucesos. Por relaciones de sucesos nos referimos a un tipo de textos ocasionales, surgidos por vez primera en la Edad Media y que gozaron de gran auge a partir del siglo XVII, que narran acontecimientos con el propósito de informar, entretener y conmover a sus receptores. Los hechos narrados podían ser reales o inventados, pero debían guardar cierta verosimilitud. La temática que trataban era muy variada: abarcaba sucesos políticos y militares, hechos de la vida de la familia real, fiestas religiosas y cortesanas, viajes y sucesos extraordinarios (catástrofes naturales, milagros, desgracias personales) (Fernández Travieso, 2008, p. 141) (Ver Figura 1).

Se publicaron miles de relaciones, en prosa o en verso, en pliego suelto de dos o cuatro hojas o en formato de libro, tantas que Víctor Infantes llegó a establecer que la condición de producto editorial era una de las características sine qua non para definirla: "una relación es un impreso breve de carácter informativo de carácter no periódico” (1996, p. 211). La definición restrictiva de la relación de sucesos, limitada a las impresas y con exclusión de las manuscritas, tiene su origen en la situación de los estudios del campo en la década de 1990. Infantes reconocía que se trataba de un área de investigación floreciente desde que Mercedes Agulló y Cobo había publicado la primera bibliografía monográfica en 1966, pero después de tres décadas no se había reflexionado sobre el concepto de relación y su existencia se daba por supuesta casi axiomáticamente. Además, constataba la gran abundancia de material: "las relaciones existen a miles, siempre habrá más relaciones de las que podamos conocer" (Infantes, 1996, p. 204). La suma de estas dos circunstancias le permitió discriminar los manuscritos y exigir que la relación fuera concebida en forma exclusiva como género editorial.

1 Este artículo se basa en mi tesis doctoral Literatura y fiesta en las márgenes del imperio: las relaciones de fiestas en Centroamérica, siglos XVII a XIX, defendida en la Universidad de Sevilla en el 2015. 
Al tratarse de un producto popular destinado a una difusión masiva se haría necesaria su impresión bajo unas determinadas condiciones de extensión, contenido, estilo, coste material, precio, etc. (Bernal Rodríguez y Espejo Cala, 2003, p. 135; Espejo Cala, 2001, p. 158). Esta definición de las relaciones como género editorial se ajusta, sin duda alguna, a la situación de España y de los ricos centros virreinales americanos, en donde la producción editorial, y específicamente la de relaciones de sucesos, fue considerable, tal vez inabarcable. Empero, limitaría las posibilidades de estudio para las regiones marginales del imperio español en las que la impresión es un fenómeno apenas apreciable a partir del siglo XIX y en donde la forma manuscrita es la única en la que se preservaron muchas relaciones ${ }^{2}$.

Aunque la existencia de narraciones de eventos concretos es mucho más antigua, el origen de las relaciones de sucesos se sitúa en el siglo XV, cuando las encontramos emparentadas directamente con las cartas o epístolas de relación o de nuevas. La epistolografía medieval no les otorgaba un estatus independiente puesto que la narratio, eje de la relación de sucesos, era solo un componente más y no el más destacado de la epístola. La narratio no se consideraba disociada de la petitio, es decir, el propósito utilitario de la epístola -la obtención del fin que se perseguía- relegaba el contenido narrativo a una posición ancilar y anclada a esquemas fosilizados. Sería en el último tercio el siglo XV cuando la carta de relación adquiriría un espacio propio y autónomo (Cátedra, 1996, p. 34).

En el siglo XVI apareció la relación de sucesos como tal y alcanzó su clímax en el XVII durante los reinados de Felipe IV y Carlos II. El surgimiento de las gacetas en el siglo XVIII marcó el declive de las relaciones, que no pudieron competir con la ampliación de la oferta informativa que significó la cobertura periódica, no esporádica, del nuevo medio comunicativo; a pesar de ello, no desaparecieron por completo y continuaron escribiéndose y publicándose, si bien en menor número, incluso hasta el siglo XIX. El número de relaciones de sucesos que se ha conservado es muy grande y se ha dicho, con toda justicia, que "fueron la 'literatura' más popular en el siglo XVII' (Fernández Travieso, 2008, p. 142).

En referencia a la conquista de América, Walter Mignolo (1982,pp. 57-110) señala una clara distinción entre las crónicas o historias, por una parte, y las cartas y relaciones por la otra. Estas últimas las divide en dos grupos: festivas y de viajes, conquista y colonización. A partir de esta caracterización con base temática se han propuesto tipologías que intentan cubrir de forma completa el fenómeno discursivo de las relaciones. José Luis Villar Piñeiro propone la existencia de tres grandes grupos: 1) festivas y de acontecimientos políticos y religiosos (que, a la vez, se subdividen de acuerdo con el motivo de la fiesta y según sea esta civil o religiosa); 2) de viajes, conquista y colonización (divididas según sean solo de viajes o de expediciones de conquista y colonización); y 3) de hechos extraordinarios o sobrenaturales (desastres naturales, milagros acaecidos por intervención divina, descripción de monstruos, etc.) (2006, p. 226).

2 Sagrario López Poza (1999, pp. 213-214) reseña la discusión en torno a las dificultades intrínsecas al establecer una definición de relación de fiestas, en especial en cuanto a su extensión y su condición o no de género editorial. Señala que una definición restrictiva dejaría fuera del género a textos que comparten idénticos destinatarios, fines y autores. Asimismo, admite que el complejo estudio de las relaciones de fiestas debe atender diversos aspectos, entre ellos el de la difusión, en donde se contempla la dualidad manuscritas / impresas. 


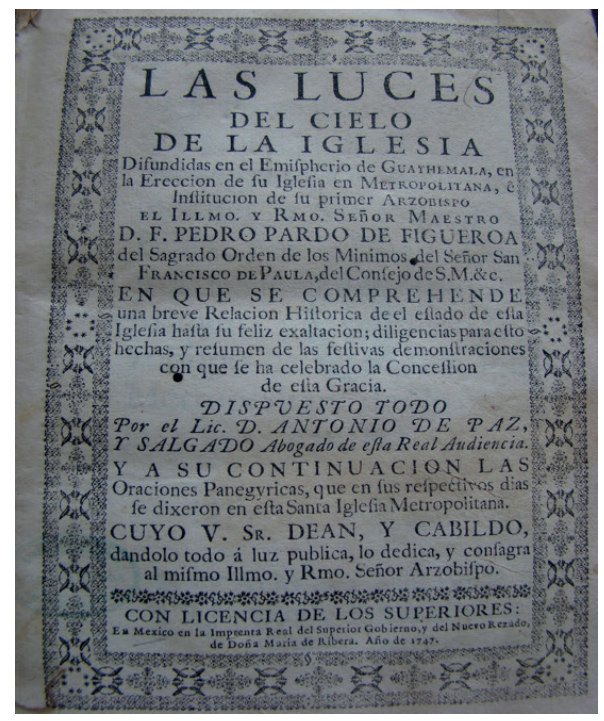

Figura 1. Portada de Las luces del cielo de la iglesia difundidas en el hemisferio de Guatemala, en la erección de su iglesia en metropolitana, e institución de su primer arzobispo, el Ilmo. y Rmo. señor maestro D.F. Pedro Pardo de Figueroa, del Sagrado Orden de los Mínimos... (1747) de Antonio de Paz y Salgado.

Biblioteca Nacional de Guatemala, Sección Antigua.

Nieves Pena Sueiro (2005, pp. 40-47) ofrece una clasificación temática más exhaustiva en la que considera las siguientes categorías:

\section{Relaciones de acontecimientos políticos y religiosos}

1.1. Acontecimientos políticos: diplomacia, tratados de paz, capitulaciones, embajadas, etc.

1.2. Acontecimientos militares: guerras, expediciones armadas, etc.

1.3. Acontecimientos religiosos: autos de fe, expulsión de los moriscos, etc.

1.4. Sátiras político-religiosas

1.5. Otros: sucesos no contemplados en las categorías anteriores

\section{Relaciones de ceremonias y festejos}

2.1. Fiestas monárquicas

2.1.1. Nacimientos de príncipes, nobles, etc.

2.1.2. Entradas públicas: recibimientos en la corte

2.1.3. Proclamaciones

2.1.4. Bodas reales

2.1.5. Exequias

2.1.6. Fiestas por victorias u otros sucesos político militares

2.2. Fiestas religiosas

2.2.1. Beatificaciones y canonizaciones

2.2.2. Traslados de imágenes

2.2.3. Consagraciones de iglesias

2.2.4. Exequias de eclesiásticos

2.2.5. Entradas públicas de eclesiásticos

2.2.6. Nombramientos

Doi: https://doi.org/10.15517/rfl.v45i2.39102 / URL: https://revistas.ucr.ac.cr/index.php/filyling/index 


\section{Relaciones extraordinarias}

3.1. Relatos de milagros

3.2. Sucesos naturales

3.3. Sucesos acontecidos a personas: "casos", desgracias personales como partos monstruosos, incestos, etc.

\section{Relaciones de viajes}

4.1. Viajes de exploración y conquista, política y espiritual

4.2. Otros viajes

En nuestra investigación sobre las relaciones de fiestas del reino de Guatemala, compilamos un corpus de cuarenta y cuatro textos, publicados entre 1663 y 1814. En consideración a la lógica narrativa desplegada por tales textos festivos, elaboramos una tipología que contempla tres modalidades discursivas: las relaciones de celebración de la muerte, las relaciones de celebración de la lealtad y las relaciones de celebración eclesiástica. Se optó por emplear en calidad de palabra marco el término "celebración" por cuanto en su carga significativa, del latín celebro, abarca un amplio campo semántico vinculado con el honrar con ceremonias, juegos o mediante discursos o escritos, cantar alabanzas, otorgar distinciones y difundir (Glare, 1992, p. 294). Este dilatado horizonte de sentidos se compagina a la perfección con la riqueza y heterogeneidad de prácticas -lingüísticas y no lingüísticas- que confluyen en el mundo festivo y permite, por ello mismo, incluir esa complejidad significativa en el presente estudio.

La tipología propuesta contiene, a partir de los rasgos de la liturgia celebratoria, tres categorías fundamentales ${ }^{3}$ :

\section{La celebración de la muerte}

1.1 Exequias reales

1.1.1 La muerte del rey

1.1.2 La muerte de la reina

1.2 Exequias de obispos

1.3 Exequias de nobles y dignatarios

\section{La celebración de la lealtad}

2.1 Cumpleaños del rey

2.2 Proclamaciones y juras

2.3 Recibimiento del real sello

\section{La celebración eclesiástica}

3.1 Proclamación episcopal

3.2 Recibimiento episcopal

3.3 Fiestas de canonización

3.4 Consagración de templos

3.5 Recepción de bulas

3 El orden escogido para la presentación de las tres categorías de relaciones festivas se adecua a la cantidad de textos publicados: las relaciones de celebración de la muerte alcanzan la veintena, en tanto que las de celebración de la lealtad no superan las quince y las eclesiásticas no son más de cuatro.

Doi: https://doi.org/10.15517/rfl.v45i2.39102 / URL: https://revistas.ucr.ac.cr/index.php/filyling/index 
De la anterior tipología se infiere que la finalidad primaria de las relaciones de sucesos es la informativa. Sin embargo, en ellas se enlazan otros propósitos que les otorgan gran complejidad: "perpetuar los acontecimientos, hacer propaganda de los poderes civil y eclesiástico, celebrar ciertos sucesos, señalar la fidelidad y adhesión de una ciudad a la corona, entretener al receptor, etc.” (Pena Sueiro, 2005, p. 44). Por encima de esa compleja urdimbre pragmática, la primacía del acontecimiento narrado y el hecho de que fueran utilizadas como fuente para la escritura de crónicas hizo que las relaciones hayan sido consideradas como un género parahistórico o protohistórico (Pena Sueiro, 2005, p. 15). También son definidas como el antecedente directo de la prensa, de allí la denominación de "preperiodismo", pues ya habían alcanzado la periodicidad y cierta continuidad temática que serán características del periodismo (Domínguez Guzmán, 2007, p. 173)4 . Para Henry Ettinghausen (2006, p. 17) las relaciones de sucesos de inicios del XVII ya son prensa propiamente dicha.

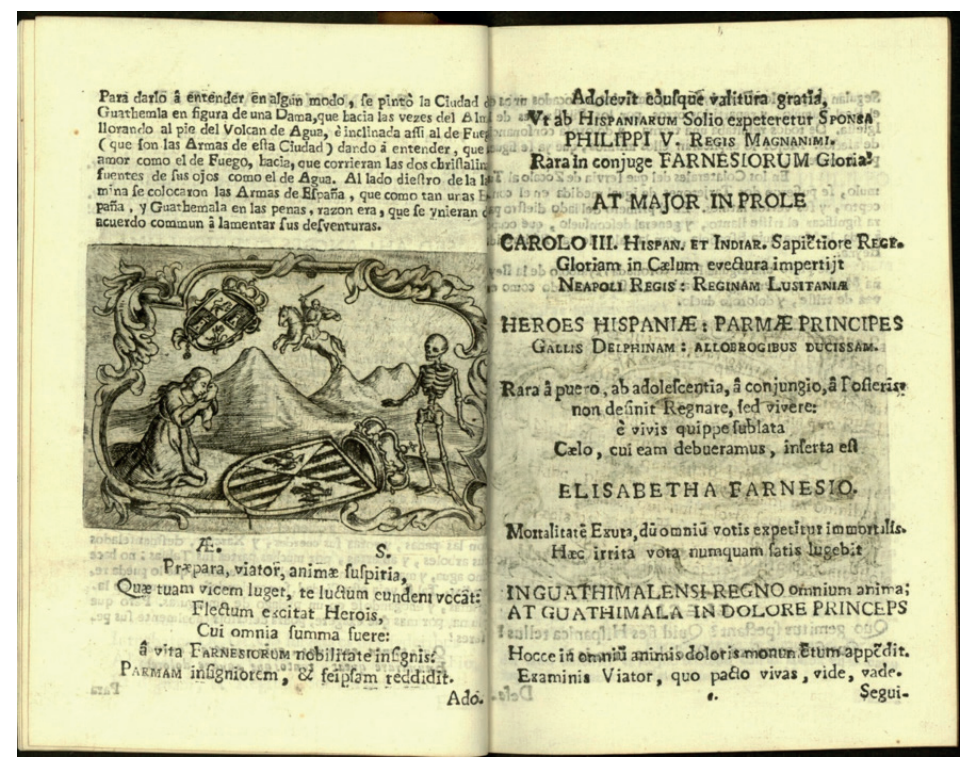

Figura 2. Portada de El sentimiento del alma y llanto de la monarquía de España en la muerte de su reina tres veces, la señora Doña Isabel Farnesio (1768) de Miguel Fernández de Córdova. Real Biblioteca de España. Copyright $(C$ Patrimonio Nacional.

Como antes se señaló, tanto cuando las relaciones de sucesos han sido vistas como fuente para el conocimiento histórico como cuando son catalogadas como texto periodístico, el énfasis ha sido puesto sobre su valor referencial. Sin embargo, también se ha aceptado que en su constitución participan elementos literarios que al combinarse con lo meramente noticioso e informativo producen un género literario, aunque sea menor y de limitado mérito estético 5

$4 \quad$ Esta idea de las relaciones de sucesos como precursoras del periodismo fue apuntada desde época temprana en los estudios sobre el tema. Mercedes Agulló y Cobo (1966) afirmaba hace más de cuatro décadas: "Las Relaciones de sucesos son el más directo e inmediato antecedente del periodismo actual. El ser testigo de un hecho, el 'yo estuve allí' ha sido siempre considerado como garantía de la realidad y la autenticidad de un suceso. Y en las Relaciones aquí recogidas veremos como el 'que se halló presente', el 'por un testigo de vista' se repiten como marchamo de los más fantásticos acontecimientos” (p. 3).

5 La calificación de "mal gusto" que pesó sobre muchos de estos textos desde su propio origen condujo a 
(ver Figura 2). En este punto, por lo tanto, resulta necesario intentar responder a una pregunta que guiará el desarrollo de la entera investigación sobre las relaciones de fiestas del reino de Guatemala: ¿en qué forma un texto que pretende reproducir un evento o una sucesión de eventos acontecidos en un espacio plenamente identificado como real y en un tiempo cercano al lector asume condición literaria? ¿Cómo es posible que la relación de sucesos, y con ella la de fiestas, considerada como antecedente directo de la prensa contemporánea, se despoje de su estatus referencial y devenga entramado discursivo ficcional?

Hans-Georg Gadamer (1997) recuerda que inicialmente existía una unidad de palabra y cosa al grado de que el nombre era percibido como parte de su portador y en realidad no sustituía a este, sino que era como él mismo. El nombre "parece en consecuencia que pertenece al ser mismo" (p. 487). Aunque la filosofía griega se inicia justamente con el cuestionamiento de esa pretendida indisolubilidad y con la afirmación de que la palabra es solo nombre y no el ser, se cae una y otra vez en la creencia en un lenguaje transparente que hace posible una reproducción fiel de la realidad material. La ilusión de un lenguaje especular, fiel trasunto de lo real, permitiría la supuesta transposición -o reducción- de la compleja referencialidad a la superficie de un texto homogéneo que se pretende plenamente aprehensible.

Con el propósito de fundamentar la consideración de un texto de pretendido estatus referencial como discurso de ficción se recurrirá a algunas de las propuestas del historiador Hayden White. Es de sobra sabido que White ha sido atacado por muchos historiadores que lo consideran el representante más visible de las corrientes posmodernas que proclaman el anti-realismo, el determinismo lingüístico y el relativismo (Riciarelli, 2010, p. 305) ${ }^{6}$. Carlo Ginzburg, por ejemplo, quien continúa las críticas de su maestro Arnaldo Momigliano contra White, le achaca un relativismo que conduce a la disciplina histórica a un callejón sin salida por negar la posibilidad de alcanzar una verdad sobre el pasado (Serna y Pons, 2000).

No interesa aquí suscribir las tesis más radicales de White en cuanto a la disolución de los límites entre la disciplina histórica y la narración literaria que convierte a la primera en una modalidad de la segunda, como cuando sostiene provocadoramente que las narrativas históricas son "ficciones verbales cuyos contenidos son tanto inventados como encontrados y cuyas formas tienen más en común con sus homólogas en la literatura que con las de las ciencias" (2003, p. 109). Sin embargo, sí resultan muy esclarecedoras para sostener la lectura como pieza literaria de un texto que en su origen se pensó como un informe de actividades realizadas por las autoridades coloniales y dirigida al distante monarca español. En otras palabras, los planteamientos básicos de White servirán para constatar cómo los textos que pretenden narrar la realidad fáctica recurren a estrategias de construcción del relato similares a las empleadas por la literatura.

White parte de la idea básica de que la narrativa no es simplemente un código comunicativo de entre los muchos que se pueden emplear para dotar de significado a la experiencia, sino que se trata de un metacódigo, "un universal humano sobre cuya base

etiquetarlos como subliteratura y determinó que los estudios especializados les prestaran poca atención durante mucho tiempo (Sánchez Pérez, 2008, p. 2).

6 Riciarelli (2010, p. 305) ofrece un compendio de algunos de los principales detractores de las tesis de White: Ginzburg, Jay, Anderson, Lorenz, Mandelbaum. En Costa Rica, también una mayoría de historiadores ha mostrado su rechazo a las ideas de White, de lo que dan cuenta las opiniones vertidas en el folleto Historia: ¿ciencia, disciplina social o práctica literaria?, compilado por Paulina Malavassi (2006). 
pueden transmitirse mensajes transculturales acerca de la naturaleza de una realidad común" (1992, p. 17). Esto significa que la narratividad se halla presente en la relación de los hechos reales al igual que en la de los ficticios. El relato histórico clásico trata de acontecimientos reales en el marco cronológico en el que sucedieron y han de narrarse, es decir, contarse "como sucesos dotados de una estructura, un orden de significación que no poseen como mera secuencia" (1992, p. 21). White toma de Paul Ricoeur la idea de que en los relatos históricos y en los ficticios se toma una secuencia de acontecimientos y se les dota de una trama: de esta forma se convierte en un relato lo que de otro modo solo sería una crónica de acontecimientos. El "entramado" dota de significado al relato, configura una representación simbólica (White, 1992, p. 182).

De acuerdo con White (2003), ya Robin G. Collingwood había indicado que el relato histórico se elabora tomando como base una serie de hechos que por sí mismos carecen de sentido y a los que se aplica lo que denominó "imaginación constructiva", esto es, un sentido de las formas diversas que las situaciones humanas pueden tomar. Sin embargo, prosigue White, Collingwood no advirtió que esos hechos históricos al ser registrados no constituyen un relato per se, pues son únicamente elementos del relato. El relato se forma cuando los acontecimientos son sometidos a un proceso de supresión y subordinación de algunos y de enfatización de otros, de caracterización, repetición de motivos, variación del tono y del punto de vista, y estrategias descriptivas. Esto significa que los acontecimientos, como componentes potenciales de un relato, son neutros - por ejemplo, no son trágicos o cómicos por definición- y que es solo la decisión del narrador de incluirlos dentro de una estructura de trama determinada lo que les impregnará una significación u otra (White, 2003, p. 113).

En consecuencia, sugiere White (2003), la tarea del historiador consiste en incorporar los hechos históricos dentro de alguno de los tipos de estructuras de trama que son reconocibles por el público al que se dirige. Esto es lo que denomina operación de "tramado". Toda secuencia histórica puede ser tramada de diferentes formas, lo que implica otorgar significaciones también diversas: mientras que Michelet construyó la revolución francesa como "un drama de trascendencia novelesca", Tocqueville la tramó como "una tragedia irónica". A partir de la selección de un tipo de relato, o trama, se seleccionan de igual forma los hechos por incluir en él. Un aspecto de gran interés es que White (2003) incluye al público como elemento determinante en la elección del tipo de trama, para lo que invoca un ejemplo: la vida de John F. Kennedy difícilmente sería aceptada como una comedia.

Este énfasis en la relevancia del público permite establecer un vínculo entre White y las teorías sobre el horizonte de expectativas y la distancia estética que la Escuela de la Recepción Alemana, con Hans R. Jauss a la cabeza, popularizó a fines de la década de 1960. El horizonte de expectativas viene a ser un convenio intersubjetivo, un sistema de normas o codificación que condiciona la experiencia estética de recepción de los textos literarios por parte de una comunidad histórica de lectores. Cada nuevo texto, por lo tanto, no aparece en un "vacío informativo", sino que, muy por el contrario, lanza al lector señales, claras u ocultas, que le suscitan recuerdos de lo ya leído (Jauss, 1976, pp. 170-171). De acuerdo con Jauss (1993), la distancia estética es la que existe entre el horizonte de expectativas presente en una comunidad de lectores y la aparición de un nuevo texto. Tal distancia se concreta históricamente en las reacciones del público y de la crítica: “éxito espontáneo, rechazo o escandalización; asentimiento aislado; comprensión paulatina o retardada" (p. 57) y puede llegar a generar un 
cambio en el horizonte de expectativas debido a que niega las experiencias familiares o a que concientiza sobre experiencias que se manifiestan por primera vez.

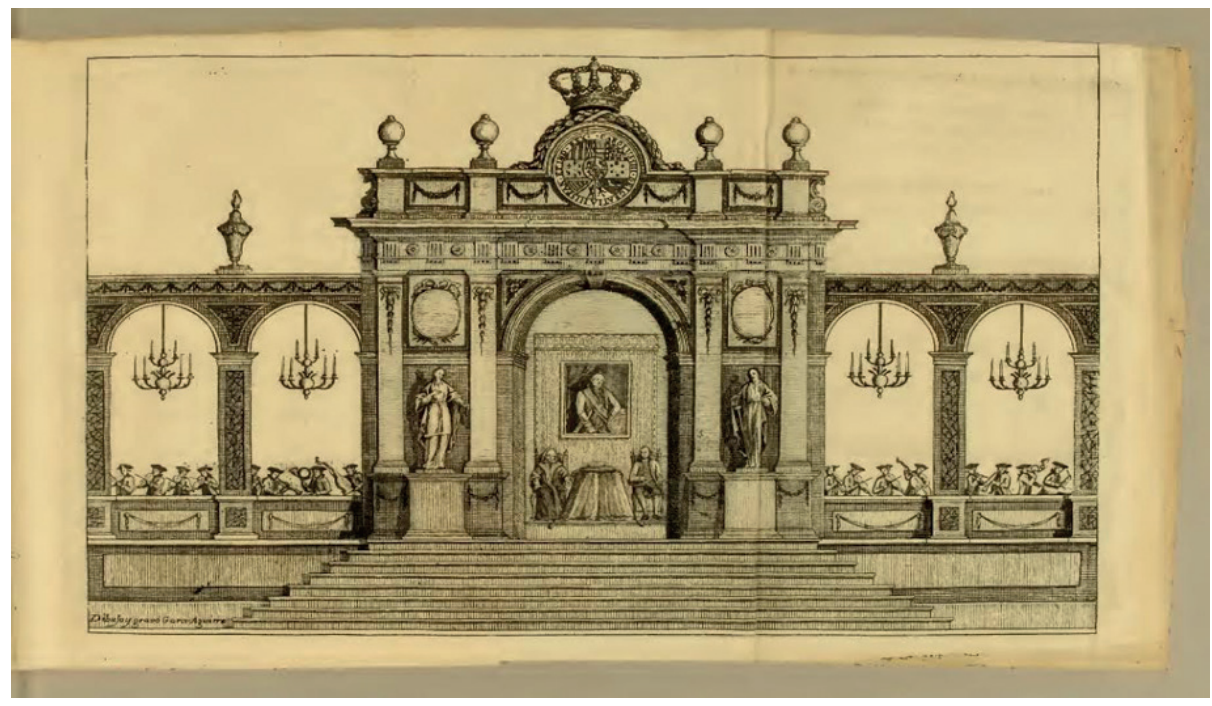

Figura 3. Arquitectura efímera en el palacio de la Real Audiencia. C. Cadena. 1793. Breve relación de la solemnidad y augusta pompa con que se recibió en la capital del reino de Guatemala el real sello de nuestro reinante católico monarca el señor Carlos IV. Guatemala: Imprenta de Ignacio Beteta. Biblioteca Nacional de Chile, Sala Medina.

Como se decía antes, los hechos no son inherentemente trágicos o cómicos, sino que dependerá de cómo sean relacionados dentro de una estructura de tramas determinada. Estas tramas, que permiten construir los acontecimientos como relatos, no son ilimitadas y, además, son "una de las formas que posee una cultura para dotar de sentido a los pasados tanto personales como públicos" (White, 2003, p. 115). Estas tramas, verdaderos pregéneros, permiten que lo extraño resulte familiar para el lector, quien no reconoce los detalles del relato, pero sí la función que cumplen como parte de un tipo de configuración que le resulta familiar. El lector, pues, identifica que el relato se ajusta a un tipo determinado (novela, tragedia, sátira, épico u otro) y eso lo hace comprensible. La selección de esa estructura por parte del historiador es, apunta White (2003), una operación literaria, productora de ficción, sin que ello implique la anulación de su valor como fuente de conocimiento.

Otro aspecto de las teorías de White que resulta fundamental para la presente investigación es el vinculado con el término clásico del tropo, del cual hace derivar los neologismos tropologizar y tropologización ${ }^{7}$. Dentro de la teoría retórica y lingüística, los tropos son desviaciones, no sancionadas por la costumbre ni por la lógica, respecto del empleo convencional del lenguaje. Sostiene White (2003), en la línea de Harold Bloom, que el tropo es una especie de defensa psicológica contra la represión que figura en el significado literal del discurso. Esta desviación no es solo respecto de ese significado que se cree "real", sino que se orienta hacia otro significado, "concepción o ideal de lo que es correcto, propio y verdadero "en realidad"' (p. 66). Lo que está en juego es la afirmación del derecho de que las

7 Esta es la traducción que ofrece Verónica Tozzi de los términos ingleses to trope y troping, respectivamente (White, 2003, p. 66). 
cosas pueden ser expresadas en una forma diferente. Esta propuesta es harto conocida para la poesía lírica, pero White (2003) señala que hasta en "la más pura prosa discursiva", despojada de todo "adorno retórico o imaginería poética", hay un fracaso en el intento por representar en un lenguaje referencial "las cosas tal como son" (p. 66). La mímesis siempre opera a partir de un proceso de inclusión y exclusión que inevitablemente deja por fuera aspectos que algún lector, autorizado o no, estimará como indispensables para una adecuada descripción del asunto tratado en cuestión. En consecuencia, toda mímesis, a despecho de su propósito realista, puede ser considerada una distorsión del fenómeno y abre paso a una nueva descripción con pretensiones de ser más realista aún (White, 2003, p. 67).

La teoría tropológica de White se enlaza de alguna forma con los aportes de la semántica cognitiva en torno a la singular relevancia de la metáfora en la comunicación cotidiana. En el campo de las teorías literarias, diferentes aproximaciones al problema de la literariedad han recurrido al concepto de metáfora. A partir del esquema funcional de Roman Jakobson (1981), se ha resaltado que si bien la función poética no es la única que define el "arte verbal", sí es "la más sobresaliente y determinante" (p. 38). La comunicación poética ha sido caracterizada, como es sabido, por su orientación hacia el mensaje mismo, y en ello juega un papel determinante la ambigüedad o violencia ejercida sobre las reglas del código lingüístico. La metáfora, por su parte, es un mecanismo fundamental para romper esa convención y propiciar, por lo tanto, la plurisignificación que define el lenguaje literario. Si bien la tradición retórica consideró la metáfora como parte de su repertorio encaminado a obtener el convencimiento y el goce estético, desde hace varias décadas se ha operado una verdadera transformación epistemológica que se tradujo en la ampliación del estudio del papel que la creación metafórica cumple dentro del conocimiento general y en otros campos de la lengua más allá del lenguaje poético. En las obras de Ortega y Gasset (Souza, 1999) y de Max Black hay indicios de este viraje, pero su articulación se debe en especial a los aportes de la semántica cognitiva difundida básicamente a partir de Metáforas de la vida cotidiana (1995), el texto clásico de Georg Lakoff y Mark Johnson.

Desde la semántica cognitiva se puede considerar la metáfora como un mecanismo de cognición básico que posibilita, en el marco de los intercambios sociales cotidianos, la comprensión de una cosa en términos de otra. La metáfora funge como un mecanismo que extiende y comunica situaciones complejas recurriendo a conceptos más cercanos y conocidos, lo que permite aumentar la producción de redes o esquemas conceptuales (Echevarría Isusquiza, 2003, párr. 5). Así que, tal y como lo adelantaba Eugenio Coseriu años antes

la actividad fantástica, la actividad poética del hombre [...] se nota en todos los individuos hablantes (no sólo en los "dioses y héroes") y en todo acto lingüístico, en la lengua literaria como en la lengua de uso corriente, en el lenguaje enunciativo como en el lenguaje emotivo (1977, p. 80).

Lo apuntado hasta ahora lleva a sostener la afirmación de White en el sentido de que "la narrativa histórica no refleja las cosas que señala; recuerda imágenes de las cosas que indica, como lo hace la metáfora" (2003, p. 125). A partir de esta idea se considerará la relación de fiestas no como fuente fidedigna para contar los hechos tal y como sucedieron, a la manera de la proclama de Leopold von Ranke, sino como texto atravesado por presupuestos ideológicos que ofrecen una percepción, entre otras posibles, de los acontecimientos. Reconocer la ficcionalidad, es decir, la presencia de elementos literarios en textos que no tienen ese origen 
no degrada su condición como guía para la comprensión de un mundo, sino que los potencia en tanto que registro de la complejidad retórica y discursiva desde la que se interpreta ese mundo.

En la relación de fiestas se enfrentan la referencialidad y la autonomía literaria, pues su propósito no es contar la fiesta tal y como sucedió, sino como debería haber sucedido, en un decidido proyecto de engrandecimiento, de hiperbolización encaminada a exaltar la importancia de los participantes y de sus demostraciones de generosidad y lealtad hacia la corona. La reconstrucción de la fiesta es la reconstrucción de la fiesta ideal, siempre superior a la efectivamente celebrada. Los recursos para lograr estos fines son eminentemente retóricos, literarios.

La relación es la concreción del acto efímero, es el intento por dotar de permanencia a la fugacidad de la multiplicidad de artes que se enlazan para hacer de la ciudad un gran escenario (ver Figura 3). La relevancia del soporte literario en el que se deja constancia de la fiesta es tal que Aurora León Alonso (1989) ha llegado a afirmar que "desde una óptica teórica, podría pensarse en la mayor importancia concedida a la permanentización del hecho mediante la Relación escrita que al transcurso festivo propiamente dicho" (p. 377). Sin llegar a tales extremos sí puede afirmarse que el relato del festejo actuaba como culmen de las representaciones: era el acto final que reunía y sistematizaba en orden cronológico y estrictamente jerarquizado los símbolos que se habían manifestado dispersos durante las festividades. Mediante el empleo de recursos literarios intentaba recrear la emoción del efímero, de modo tal que superaba la condición de mera acta notarial, de transcripción puntual, y funcionaba como "recreación imaginativa del evento" (García Bernal, 2006, p. 579).

La ampliación del corpus de la literatura colonial centroamericana que permite esta perspectiva teórica ha sido puesta en práctica en nuestra investigación Literatura y fiesta en las márgenes del imperio: las relaciones de fiestas en Centroamérica, siglos XVII a XIX (2015). Este trabajo se ofrece como una primera aproximación, de carácter panorámico, al fenómeno de la fiesta barroca contada dentro de los límites administrativos del reino de Guatemala. Como punto de partida, se constituyó un corpus del mayor número posible de relaciones de fiestas impresas. Una intensa búsqueda por depósitos bibliográficos a ambos lados del Atlántico arrojó como resultado un repertorio conformado por cuarenta y cuatro relaciones, de las cuales treinta y siete corresponden a festejos de la capital del reino en sus dos asientos -Santiago de los Caballeros y Nueva Guatemala de la Asunción-, en tanto que dos son de Chiapas, dos de El Salvador y tres de Nicaragua. No ha sido posible localizar, hasta el momento presente, ninguna relación impresa de festejos celebrados en Honduras y Costa Rica, lo que explica la ausencia de toda mención a dichas jurisdicciones.

El catálogo se organizó, a partir de criterios retóricos -la construcción de la dispositio y la elocutio- y temáticos, en tres categorías fundamentales: las relaciones de celebración de la muerte, las relaciones de celebración de la lealtad y las relaciones de celebración eclesiástica. A partir de esta tipología, se formuló un esbozo de la evolución secular de la relación festiva en Centroamérica, subrayando sus inflexiones y rupturas. Este es un primer paso para que la apertura del corpus se enriquezca con la incorporación de otros géneros discursivos, tales como los restantes subgéneros de las relaciones de sucesos, la oratoria sacra, la hagiografía y las probanzas de méritos. 


\section{Bibliografía}

Agulló y Cobo, M. (1966). Relaciones de sucesos. I: Años 1477-1619. Madrid, España: CSIC.

Bernal Rodríguez, M. y Espejo Cala, C. (2003). Tres relaciones de sucesos del siglo XVII. Propuesta de recuperación de textos preperiodísticos. IC Revista Científica de Información y Comunicación, 1, 133-176.

Cátedra, P. M. (1996). En los orígenes de las epístolas de relación. En M. C. García de Enterría et al. (Ed.). Las relaciones de sucesos en España (1500-1750). Actas del Primer Coloquio Internacional (Alcalá de Henares, 8, 9 y 10 de junio de 1995) (pp. 33-64). Alcalá de Henares: España.

Coseriu, E. (1977). El hombre y su lenguaje. Estudios de teoría y metodología lingüística. Madrid, España: Editorial Gredos.

Domínguez Guzmán, A. (2007). El preperiodismo en España a finales del Quinientos: las relaciones de sucesos impresas por Rodrigo de Cabrera. En P. Bolaños, A. Domínguez y M. de los R. (Eds.). Geh hin und lerne. Homenaje al profesor Klaus Wagner (pp. 165-192). Sevilla, España: Secretariado de Publicaciones de la Universidad de Sevilla.

Echevarría Isusquiza, I. (2003). Acerca del vocabulario español de la animalización humana. Círculo de lingüística aplicada a la comunicación, (15). Recuperado de http://webs. ucm.es/info/circulo/nol5/echevarri.htm

Espejo Cala, C. (2001). El origen epistolar de las relaciones de sucesos de la edad moderna. En C. Sáez y A. Castillo Gómez (Eds.). Actas del VI Congreso Internacional de Historia de la Cultura Escrita. Vol. I. La correspondencia en la historia. Modelos y prácticas de la escritura epistolar (pp. 157-168). Alcalá de Henares, España: Calambur Editorial.

Ettinnghausen, H. (2006). 'Tabloids' y 'Broadsheets': la prensa española y sus lectores en el primer tercio del siglo XVII. En P. Bégrand (Ed.). Las relaciones de sucesos. Relatos fácticos, oficiales y extraordinarios. Encuentro internacional sobre relaciones de sucesos. Besançon, 19-20 de septiembre de 2003 (pp. 17-33). Francia: Presses Universitaires de Franche-Comté.

Fernández Travieso, C. (2008). Relaciones de Sucesos españolas en el norte de Italia: las Relaciones de Sucesos de la Biblioteca Nazionale Braidense de Milán. Península. Revista de Estudios Ibéricos, 5, 141-156.

Gadamer, H. G. (1997). Verdad y método I. Salamanca, España: Ediciones Sígueme.

García Bernal, J. J. (2006). El fasto público en la España de los Austrias. Sevilla, España: Secretariado de Publicaciones de la Universidad de Sevilla.

Glare, P. G. W. (Ed.). (1992). Oxford Latin Dictionary. Oxford: OUP Oxford.

Infantes, V. (1996). ¿Qué es una relación? (Divagaciones varias sobre una sola divagación). En M.C. García de Enterría et al. (Eds.). Las relaciones de sucesos en España (15001750). Actas del Primer Coloquio Internacional (Alcalá de Henares, 8, 9 y 10 de junio de 1995) (pp. 203-216). Alcalá de Henares, España: Servicio de Publicaciones de la Universidad de Alcalá y Publications de La Sorbonne.

Jakobson, R. (1981). Lingüística y poética. Madrid, España: Ediciones Cátedra. 
Jauss, H. R. (1976). La literatura como provocación. Barcelona, España: Ediciones Península.

Jauss, H. R. (1993). Historia de la literatura como una provocación a la ciencia literaria. En D. Rall (Ed.). En busca del texto. Teoría de la recepción literaria (pp. 55-58). México: Universidad Nacional Autónoma de México.

Lakoff, G. y Johnson M. (1995). Metáforas de la vida cotidiana. Madrid, España: Cátedra.

León Alonso, A. (1989). Reflexiones acerca de la iconografía y literatura de fiestas durante el Antiguo Régimen. Revista virtual de la Fundación Universitaria española. Cuadernos de arte e iconografía, 3, 376-381.

López Poza, S. (1999). Peculiaridades de las relaciones festivas en forma de libro. En S. López Poza y N. Pena Sueiro (Eds.). La fiesta. Actas del II Seminario de Relaciones de Sucesos (A Coruña, 13-15 de julio de 1998) (pp. 213- 222). Ferrol, España: Sociedad de Cultura Valle Inclán.

Malavassi, P. (Ed.). (2006). Historia: ¿ciencia, disciplina social o práctica literaria? San José, Costa Rica: Editorial de la Universidad de Costa Rica.

Mignolo, Walter. (1982). Cartas, crónicas y relaciones del descubrimiento y la conquista. En L. Iñigo Madrigal (Ed.). Historia de la Literatura hispanoamericana. Tomo I (pp. 57-116). Madrid, España: Cátedra.

Pena Sueiro, N. (2005). Repertorio de Relaciones de Sucesos españolas en prosa impresas en pliegos sueltos en la Biblioteca Geral Universitaria de Coimbra (siglos XVI-XVIII). Madrid, España: Fundación Universitaria Española.

Riciarelli, C. (2010). Hayden White y Verónica Tozzi o el vuelo del ñandú. El Títere y el Enano. Revista de Teología Crítica, 1, 305-318.

Sánchez Mora, A. (2015). Literatura y fiesta en las márgenes del imperio: las relaciones de fiestas en Centroamérica, siglos XVII a XIX. (Tesis doctoral). Universidad de Sevilla, España.

Sánchez Pérez, M. (2008). La poética de las relaciones de sucesos tremendistas en pliegos sueltos poéticos (siglo XVI): construcción y relaboración. Etiópicas. Revista de Letras Renacentistas, 4, 1-20.

Serna, J. y Pons, A. (2000). Cómo se escribe la microhistoria. Ensayo sobre Carlo Ginzburg. Madrid, España: Cátedra-Universitat de Valencia.

Souza, M. (1999). La metáfora en Ortega y Gasset: qué dice el poeta al decir que el ciprés es una llama muerta. Contexto, 6(23), 20-36.

Villar Piñeiro, J. L. (2006). Las noticias en la América colonial: dos relaciones de temática indígena. En S. López Poza (Ed.). Las noticias en los siglos de la imprenta manual. Homenaje a Mercedes Agulló, Henry Ettinghausen, Ma. Cruz García de Enterría, Giuseppina Ledda, Augustin Redondo y José Simón (pp. 223-229). A Coruña, España: SIELAE y Sociedad de Cultura Valle Inclán.

White, H. (1992). El contenido de la forma. Narrativa, discurso y representación histórica. Barcelona, España: Ediciones Paidós.

White, H. (2003). El texto histórico como artefacto literario y otros escritos. Barcelona, España: Ediciones Paidós. 
